\title{
PRESERVAÇÃO E CONSERVAÇÃO DOS PRONTUÁRIOS DO SERVIÇO DE ARQUIVO MÉDICO E ESTATÍSTICA DO HOSPITAL UNIVERSITÁRIO PROFESSOR ALBERTO ANTUNES
}

PRESERVATION AND CONSERVATION OF PRUNCTUARIES OF THE MEDICAL ARCHIVE AND STATISTICS SERVICE AT THE UNIVERSITY HOSPITAL PROFESSOR ALBERTO ANTUNES

\author{
Márcia Aparecida Vargas dos Santos \\ Universidade Federal de Alagoas (UFAL) \\ Brasil \\ Francisca Rosaline Leite Mota \\ Universidade Federal de Alagoas (UFAL) \\ Brasil \\ Nelma Camêlo de Araujo \\ Universidade Federal de Alagoas (UFAL) \\ Brasil
}

Submetido em: 29/05/2020

Aceito em: 29/07/2020

Publicado em: 12/10/2020

Licença:

(c) (7) (5)

Autor para correspondência: Márcia Aparecida Vargas dos Santos

Email: mavargassantos@hotmail.com

ORCID: https://orcid.org/0000-0001-9392-6774

Como citar este artigo:

SANTOS, Márcia Aparecida Vargas dos; MOTA, Francisca Rosaline Leite; ARAUJO, Nelma Camêlo de. Preservação e conservação dos prontuários do serviço de arquivo médico e estatística do Hospital Universitário Professor Alberto Antunes.

REBECIN, São Paulo, v. 7, número especial, p. 4-23, 2020. DOI: 10.24208/rebecin.v7iespecial.184. 


\title{
RESUMO
}

A Gestão de Documentos, juntamente com medidas de preservação e conservação, minimiza tempo e espaço, agiliza a recuperação da informação e reflete diretamente no processo de tomada de decisão dos gestores de toda e qualquer instituição. Este artigo buscou estudar a gestão de documentos e os mecanismos de preservação e conservação dos prontuários do Serviço de Arquivo Médico e Estatística (SAME), do Hospital Universitário Professor Alberto Antunes da Universidade Federal de Alagoas (UFAL), com vistas a salvaguardar a memória institucional. A metodologia utilizada foi exploratória, com abordagem qualitativa e uma extensa pesquisa bibliográfica. A análise dos dados aponta para: a necessidade de maiores esforços no sentido de prover infraestrutura tecnológica adequada para o processo de Gestão Eletrônica de Documentos; importante atuação de docentes e discentes do Curso de Biblioteconomia e; interesse da instituição em relação à preservação e conservação dos prontuários guardados pelo SAME/HUPAA/UFAL.

Palavras-Chave: Arquivo de Instituições de Saúde. Digitalização de Prontuário. Gestão Documental. Prontuário do Paciente.

\begin{abstract}
Document Management, together with preservation and conservation measures, minimizes time and space, speeds up information retrieval and reflects directly on the decision-making process of the managers of each and every institution. This article sought to study Document management and mechanisms for the preservation and conservation of medical records from the Medical Archive and Statistics Service (SAME), at the Professor Alberto Antunes University Hospital of the Federal University of Alagoas (UFAL), with a view to safeguarding institutional memory. The methodology used was exploratory, with a qualitative approach and extensive bibliographic research. The data analysis points to: the need for greater efforts in order to provide adequate technological infrastructure for the Electronic Document Management process; important performance of professors and students of the Librarianship Course and; the institution's interest in the preservation and conservation of the medical records kept by SAME / HUPAA / UFAL.
\end{abstract}

Keywords: Health Institutions Archive. Medical Record Scanning. Document management. Patient Record.

\section{INTRODUÇÃO}

A informação tem um conceito interdisciplinar, pois é utilizada em todos os campos científicos, apresentando diversificadas definições. A informação em saúde, em especial, evolui com destacada rapidez em comparação a algumas outras áreas. Neste sentido, existe a necessidade premente de adotar métodos para coletar, armazenar, tratar e disseminar a informação que será utilizada por diferentes públicos, desde pesquisadores, professores, estudantes, profissionais de saúde até os pacientes. A informação em saúde deve ser registrada em suportes analógicos ou digitais que possam ser geridos de modo a auxiliar na tomada de decisão, com vistas 
a promover melhorias na gestão em saúde e, consequentemente, proporcionar benefícios à população atendida. No âmbito hospitalar, esta é uma necessidade básica.

O Serviço de Arquivo Médico e Estatística do Hospital Universitário Professor Alberto Antunes da Universidade Federal de Alagoas - Empresa Brasileira de Serviços Hospitalares (SAME/HUPAA/UFAL/EBSERH) é um dos mais importantes e estratégicos setores de atividades dentro da instituição. E, sendo assim, é indiscutível a necessidade de pleno gerenciamento documental dos Prontuários de Pacientes com vistas a proporcionar o maior nível de segurança possível no tratamento, acondicionamento, disponibilização e acesso às informações no âmbito interno/intersetorial do hospital, possibilitando melhoria dos processos de trabalho e, consequentemente, do atendimento aos pacientes, razão maior da existência da instituição.

A produção de documentos impressos cresce vertiginosamente, e os documentos resultantes dessa produção não conseguem ser armazenados de forma adequada, na maioria das vezes por não existir espaço suficiente para guarda física. Com as novas tecnologias surgem os arquivos digitais, com uma proposta de armazenamento e preservação documental com acesso mais rápido e fácil à informação. Isto demanda um significativo grau de investimentos em equipamentos de hardware e software, bem como, o atendimento às exigências estabelecidas na Lei 13.787 de 27 de dezembro de 2018 que dispõe sobre a digitalização e a utilização de sistemas informatizados para a guarda, o armazenamento e o manuseio de prontuário de paciente. É importante atentar para o Decreto 10.278 de 18.03.2020 que Regulamenta o disposto no inciso $X$ do caput do art. 3ํㅡ da Lei $n^{0} 13.874$, de 20 de setembro de 2019, e no art. $2^{-}$-A da Lei no 12.682, de 9 de julho de 2012, para estabelecer a técnica e os requisitos para a digitalização de documentos públicos ou privados, a fim de que os documentos digitalizados produzam os mesmos efeitos legais dos documentos originais.

O SAME/HUPAA/UFAL/EBSERH possui um acervo com aproximadamente 900.000 (novecentos mil) Prontuários de Pacientes mantidos na fase permanente, dentre os quais estão os Prontuários do Navio SS Hope, que datam de 1972/1973, retratando toda a trajetória histórica de atendimento em saúde do Hospital, bem como 
o marco inicial para a construção do Hospital Universitário. É o setor responsável em manter os prontuários dos pacientes de forma acessível e ordenada, movimentando diariamente uma média de 2.000 (dois mil) prontuários.

Frente a pandemia do Coronavírus no mundo, a Empresa Brasileira de Serviços Hospitalares (EBSERH) instituição responsável pela administração do Hospital Universitário Professor Alberto Antunes (HUPAA), emitiu uma nota de procedimentos em 16/04/2020, orientando os procedimentos no uso e manuseio dos prontuários do paciente que circulam na instituição. Tal documento é mais um indicativo da necessidade de proporcionar tratamento adequado aos prontuários existentes no SAME dos hospitais. Nesse sentido, esse trabalho se propõe a corroborar a importância do SAME e urgência da adoção de uma política de Gestão e Preservação de Documentos, tomando por base primordial os processos de higienização e preparação dos prontuários para digitalização.

Para realização do estudo traçou-se como objetivo geral estudar a importância dos processos de gestão de documentos com vistas a salvaguardar a memória da saúde de Alagoas, bem como, a memória institucional do HUPAA/UFAL/EBSERH. Para tanto, a metodologia utilizada foi exploratória, com abordagem qualitativa e uma extensa pesquisa bibliográfica que possibilitou a construção do referencial teórico ora apresentado. Foram aplicados questionários junto aos profissionais que atuam no SAME da instituição e foi possível comprovar a importância e necessidade da adoção de medidas para o tratamento adequado dos documentos. Todos esses elementos são abordados no decorrer da estrutura textual do presente artigo.

\section{GESTÃO DE DOCUMENTOS EM INSTITUIÇÕES DE SAÚDE}

A explosão da informação, após a Segunda Guerra Mundial, acelerou o processo tecnológico. Fonseca (2005, p. 17) diz que essa conjuntura "exigia meios cada vez mais sofisticados e rápidos para que a informação científica e tecnológica pudesse ser usada como recurso econômico e político". As causas dos marcos históricos do crescimento de informações foram o surgimento do papel e a invenção dos computadores, que facilitaram a grande produção de documentos. Com toda essa evolução, o conceito de arquivos sofre modificações para atender aos desafios e 
soluções no controle, dentro das organizações públicas ou privadas, do montante documental crescente com ênfase na gestão de documentos.

O poder público, a área privada e até mesmo pessoas físicas, são forçados a guardar cada vez mais um volume expressivo de documentos. Em face ao dilema do que fazer com o acúmulo de documentos, o Artigo $3^{\circ}$ da Lei Federal $n^{\circ} 8.159$ conceitua: "Considera-se gestão de documentos o conjunto de procedimentos e operações técnicas referentes à sua produção, tramitação, uso, avaliação e arquivamento em fase corrente e intermediária, visando a sua eliminação ou recolhimento para guarda permanente".

Para uma compreensão melhor, citam-se alguns artigos da lei que aborda a gestão de documentos:

Art. $1^{\circ}$ Lei $\mathbf{n}^{\circ}$ 8.159/91: "É dever do Poder Público a gestão documental e a de proteção especial a documentos de arquivos, como instrumento de apoio à administração, à cultura, ao desenvolvimento científico e como elementos de prova e informação".

Art. $4^{\circ}$ Lei $\mathrm{n}^{\circ}$ 8.159/91: "Todos têm direito a receber dos órgãos públicos informações de seu interesse particular ou de interesse coletivo ou geral, contidas em documentos de arquivos, que serão prestadas no prazo da lei, sob pena de responsabilidade, ressalvadas aquelas cujo sigilo seja imprescindível à segurança da sociedade e do Estado, bem como à inviolabilidade da intimidade, da vida privada, da honra e da imagem das pessoas".

Art. $6^{\circ}$ Lei $n^{\circ}$ 8.159/91: "Fica resguardado o direito de indenização pelo dano material ou moral decorrente da violação do sigilo, sem prejuízo das ações penal, civil e administrativa". (BRASIL, 2004)

A gestão de documentos está ligada diretamente ao uso de técnicas arquivística que facilitam a localização, o acesso às informações, a relação com outros documentos, evitando perdas, prazos e acúmulo de documentos. Destacamos três fases básicas da gestão de documentos: a produção, a utilização e a destinação.

a) Produção de documentos: essa fase tem por objetivo prevenir a criação de documentos que não são essenciais, são definidas normas que vão desde as características físicas do suporte até as formas de registro da informação, reduzindo, assim, o volume dos documentos que serão manipulados, controlados, armazenados e destinados, intensificando o uso e valor documental que são necessários, garantindo o uso de materiais apropriados na confecção dos documentos, garantindo a integridade e a preservação dos mesmos, e assegurando a utilização apropriada da digitalização ao longo do ciclo de vida dos documentos; 
b) Utilização dos documentos: envolve o controle, uso e armazenamento de documentos essenciais no desenvolvimento das atividades de uma instituição, abrange medidas na disponibilização dos documentos e informações no desenvolvimento das funções da instituição, o uso efetivo da informação e arquivos correntes, bem como a seleção do material, de equipamentos e local de armazenagem dos documentos, está ligado à recuperação da informação através de plano de classificação padronizada para a instituição;

c) Destinação dos documentos: essa fase envolve as decisões em relação a quais documentos devem ser preservados permanentemente como memória da instituição, ou seja, compreende a avaliação, a seleção e a determinação do prazo de guarda, tendo como produto a Tabela de Temporalidade (PAES, 2004, p. 53-54).

Essa deliberação deve ser fundamentada pela Tabela de Temporalidade, que é um "Instrumento de destinação, aprovado por autoridade competente, que determina prazos para transferência, recolhimento, eliminação e reprodução de documentos". (CAMARGO; BELLOTTO, 1996, p.72). É uma ferramenta essencial na Gestão Documental, pois é através dela que são determinados prazos para eliminação ordenada e racional de documentos dentro de uma instituição. É um instrumento normativo elaborado por profissionais de diversas áreas (jurídica, administrativa e contábil) com o auxílio de historiadores e coordenação dos arquivistas.

O Conselho Federal de Medicina, juntamente com o Conselho Nacional de Arquivos, editou a Resolução $n^{\circ} 22$, que estabelece, no seu artigo $3^{\circ}$, as competências da Comissão de Permanente de Avaliação de Documentos:

Art. $3^{\circ}$ No que se refere ao estabelecimento de temporalidade e destinação final dos prontuários de pacientes, independente da forma ou do suporte, compete à Comissão Permanente de Avaliação de Documentos:

a) analisar os conjuntos documentais, determinando os respectivos prazos de guarda e destinação;

b) identificar os valores primário e secundário, segundo o seu potencial de uso; considerando por valor primário o uso administrativo para a instituição, razão primeira da criação do documento, e valor secundário o uso para outros fins que não aqueles para os quais os documentos foram criados, podendo ser probatório e informativo;

c) estabelecer critérios para análise e avaliação dos documentos e sua destinação final, considerando os requisitos previstos no art. $2^{\circ}$ desta resolução;

d) elaborar Tabela de Temporalidade e Destinação de Documentos, Listagem de Eliminação de Documentos, Edital de Ciência de Eliminação e Termo de Eliminação de Documentos, quando for o caso, e relatório final da Comissão; 
e) revisar, periodicamente, a Tabela de Temporalidade e Destinação de Documentos, em função da produção ou supressão de novos documentos, e da evolução da legislação e dos procedimentos médicos (CONARQ, 2005).

O artigo 9º da Resolução CFM no 1.821 veio estabelecer que:

as atribuições da Comissão Permanente de Avaliação de Documentos nas unidades que prestam assistência médica e são detentoras de arquivos de prontuários de pacientes, tomando como base as atribuições estabelecidas na legislação arquivística brasileiras, podem ser exercidas pela Comissão de Revisão de Prontuários (CFM, 2007).

A Resolução no 22 do CONARQ considera como requisitos necessários para o desenvolvimento do processo de avaliação:

I - conhecer os objetivos, a estrutura e o funcionamento da instituição detentora dos documentos;

II - conhecer a organização dos conjuntos documentais a serem avaliados, incluídos os métodos de classificação adotados, bem como sua importância para fins de prova, de informação, e de estudos e pesquisas nas áreas das ciências da saúde, humanas e sociais;

III - conhecer a terminologia e os procedimentos da área médica, bem como de suas especialidades;

IV - conhecer a legislação pertinente à concessão de direitos relativos aos indivíduos portadores de necessidades especiais e de doenças graves e terminais (CONARQ, 2005).

É de extrema valia que a Comissão de Revisão de Prontuários seja instituída e se faça realmente atuante no processo de avaliação deste importantíssimo tipo de documento. A Lei № 13.787, de 27 de dezembro de 2018, deixa claras as atribuições desta comissão. Vejamos:

Art. 3o Os documentos originais poderão ser destruídos após a sua digitalização, observados os requisitos constantes do art. 2o desta Lei, e após análise obrigatória de comissão permanente de revisão de prontuários e avaliação de documentos, especificamente criada para essa finalidade. $\S 1$ A comissão a que se refere o caput deste artigo constatará a integridade dos documentos digitais e avalizará a eliminação dos documentos que os originaram.

$\S 2^{\circ}$ Os documentos de valor histórico, assim identificados pela comissão a que se refere o caput deste artigo, serão preservados de acordo com o disposto na legislação arquivística.

Fica patente que é necessária uma análise criteriosa e que a memória institucional considera a guarda de documentos dotados de valor histórico. $\mathrm{E}$ tal valor histórico só poderá ser avaliado e atribuído por esta comissão. Ressalta-se que a Comissão de Revisão de Prontuários pode e deve caminhar junto à Comissão 
Permanente de Avaliação de Documentos que é responsável pela análise de todas as demais tipologias documentais existentes na instituição de saúde.

\section{O PAPEL DO SAME E DAS COMISSÕES DE AVALIACCÃO DE DOCUMENTOS E REVISÃO DE PRONTUÁRIOS DO HOSPITAL UNIVERSITÁRIO PROFESSOR ALBERTO ANTUNES}

O Serviço de Arquivos Médicos e Estatísticos (SAME) surgiu no Brasil em 1943, quando os arquivos médicos foram separados da estatística. Criou-se a centralização desses setores e registro geral num único órgão, o SAME, tornando-se a memória do hospital. As instituições passaram a usar esses serviços, obtendo excelentes resultados na avaliação do seu padrão de qualidade (FRANÇA, 2014).

O primeiro hospital a arquivar dados clínicos e organizar um Serviço de Arquivo Médico e Estatístico foi o Hospital Geral de Massachusetts, nos Estados Unidos, em 1987. No Brasil, o primeiro hospital a implantar o SAME foi o Hospital das Clínicas da Universidade de São Paulo, em 1943 (FRANÇA, 2014).

O SAME é imprescindível dentro da instituição de saúde. Ele permite que todo e qualquer profissional adquira a informação desejada, dando-Ihe aplicabilidade e atendendo com eficácia os pacientes que recorrem à instituição.

Segundo França (2014, p. 24), em algumas unidades de saúde o SAME tem a função de "organizar auditorias administrativas, fazer levantamento de consultas realizadas, armazenar dados obtidos, produzir prontuários médicos e a guarda desses, permitindo sua rastreabilidade sempre que necessário."

Nesse sentido, França (2014, p. 24) afirma que "o SAME é primordial para uma unidade de saúde, é deste setor que sai toda e qualquer decisão que a administração vem tomar para o bem da instituição e de seu usuário".

O SAME/HUPAA/EBSERH é um dos mais importantes e estratégicos setores de atividades dentro do Hospital Universitário Professor Alberto Antunes. E sendo assim, é indiscutível a necessidade de pleno gerenciamento documental dos prontuários de paciente com vistas a proporcionar o maior nível de segurança possível no tratamento, acondicionamento, disponibilização e acesso às informações no âmbito interno/intersetorial do hospital, possibilitando melhoria dos processos de trabalho e, consequentemente, do atendimento aos pacientes, razão maior da existência da instituição. 
O SAME/HUPAA/EBSERH possui em seu acervo aproximadamente 900 mil prontuários de pacientes distribuídos em áreas distintas, sendo os considerados ativos arquivados próximos à Coordenação da Unidade de Regulação Assistencial (URA) e, os considerados inativos, localizados na CAFUA, dentre os quais estão os Prontuários do Navio SS Hope, que datam do ano de 1972/1973, retratando toda a trajetória Histórica de atendimento em saúde do Hospital, bem como o marco inicial para a construção do Hospital Universitário.

No que se refere aos arquivos de instituições de saúde, temos, para além do CONARQ, as normativas preconizadas pelo Conselho Federal de Medicina (CFM) e a Sociedade Brasileira de Informática em Saúde (SBIS). Partindo da importância social dos documentos na área da saúde, foi possível aplicar técnicas de higienização aos prontuários utilizando o material próprio para esse fim, para preservar e conservar, evitando uma possível restauração dos documentos, bem como iniciar o processo de digitalização para uma recuperação da informação por meio eletrônico.

A Comissão de Avaliação de Documentos de Arquivo (CPAD) é integrada por arquivista responsável pela guarda dos documentos, servidores das unidades administrativas que se refere à documentação, historiador ligado à área de pesquisa, profissional da área jurídica responsável pelo valor legal dos documentos e profissionais com conhecimento do acervo avaliado.

O HUPAA/UFAL/EBSERH, legitimou, através da Portaria GS nํ133, de 30 de maio de 2018, a Comissão Permanente de Avaliação de Documentos (CPAD) e a Comissão de Revisão de Prontuários (CRP), atendendo à Resolução CFM № 1638/2002. Houve uma junção entre essas duas comissões, sendo denominada de Comissão de Revisão de Prontuários e Avaliação Permanente de Documentos (CRP). Importante dizer que a CRP já existia na instituição e foi incorporada à CPAD em virtude da necessidade da execução do projeto "Tratamento e organização dos prontuários de pacientes do HUPAA/UFAL/EBSERH". O referido projeto foi coordenado pela Professora do Curso de Biblioteconomia da UFAL e pela Chefe da Unidade de Regulação Assistencial/HUPAA/EBSERH e Coordenadora do SAME/HUPAA/EBSERH. Uma das primeiras condições para a execução do projeto foi a existência de tal comissão, que passou a atuar desde sua criação e já conseguiu tomar várias medidas para que o processo de Gestão Documental seja o melhor 
possível, atendendo todos os trâmites preconizados pelo Conselho Nacional de Arquivos (CONARQ), sobretudo no que diz respeito ao processo de descarte de documentos.

Em novembro de 2018 a comissão realizou uma visita Técnica, com a finalidade de conhecer o local de guarda, a estrutura física e as condições de manutenção e arquivamento dos prontuários considerados inativos na Cafua do SAME. Durante a visita, após análise do material, foi sugerida a elaboração de laudo para a efetuação do descarte dos prontuários considerados irrecuperáveis. Com base no laudo técnico, foi aprovado pela comissão e homologado pela Superintendência do HUPAA/UFAL/EBSERH, o descarte de aproximadamente 3 (três) toneladas e meia de documentos que não estavam em nenhuma condição de permanência junto ao arquivo. Segundo o Laudo, os lotes estavam em estado avançado de deterioração e não poderiam ser recuperados.

De acordo com o Laudo chegou-se à seguinte constatação em relação ao arquivo inativo (Cafua): ambiente altamente insalubre com a necessidade de executar o descarte dos materiais acima relacionados para garantir, minimamente, as condições de respiração e trabalho no ambiente. Os documentos estavam apodrecidos e comprometiam o ambiente de trabalho, bem como, proporcionavam a proliferação extensiva de fungos, bactérias e insetos, comprometendo os demais documentos que se encontram em condições mínimas de conservação. A manutenção de documentos em estado de putrefação pode incidir diretamente nos demais documentos, podendo causar danos ainda maiores ao acervo, prejudicando qualquer possiblidade de salvaguardar os demais itens documentais.

O Laudo - Visita Técnica mencionado foi encaminhado à CPAD e CRP para execução dos trâmites oficiais de descarte dos Lotes 0001, 0002, 0003 de documentos acondicionados no arquivo inativo (cafua).

É importante ressaltar que nenhum documento pode ser descartado sem a avaliação da CPAD e da CRP. A CRP está trabalhando na avaliação dos prontuários para identificar quais são aqueles que possuem valor histórico para a instituição. $A$ comissão é presidida pela Dra. Márcia Rebelo, que faz parte da estrutura administrativa do Hospital Universitário Professor Alberto Antunes e por representantes de diversos setores. A comissão também elaborou o regimento interno 
onde estão registradas todas as suas atribuições. As reuniões são realizadas mensalmente.

Em se tratando da Comissão de Revisão de Prontuários (CRP) Santos e Freixo (2011, p.8) fazem a seguinte colocação:

A Comissão de Revisão de Prontuários tem natureza consultiva, deliberativa, normativa, educativa e independente, constituída com a finalidade de analisar, acompanhar e avaliar o preenchimento e a qualidade dos prontuários dos pacientes. A atuação da Comissão de Revisão de Prontuários deve prover as unidades de arquivo e demais profissionais de orientação para as ações e procedimentos referentes à avaliação documental, além de indicar procedimentos para melhorar a qualidade dos prontuários, mantendo estreita relação com a Comissão de Ética Médica da unidade para discussão dos resultados das avaliações realizadas.

Os membros da Comissão de Revisão de Prontuários (CRP) são designados pela Coordenação da instituição de saúde, e em geral, é composta por médicos que atuam em diferentes especialidades, enfermeiros e outros profissionais, além do Coordenador do Serviço de Arquivo Médico e Estatístico (SAME) e do Serviço de Registro e Informações em Saúde (SRIS).

A guarda dos documentos é determinada pelo valor dos mesmos de acordo com a frequência de uso das informações neles contidas, leis e decretos que regulem sua prescrição legal, mediante a existência de outras fontes com as mesmas informações e a guarda por precaução, em face das práticas administrativas.

Conforme Nota Técnica $n^{\circ} 02 / 2020$ da EBSERH, sobre o manuseio e armazenamento dos prontuários dos pacientes, as orientações são:

Recomenda-se que, os prontuários físicos ou eletrônicos permaneçam em local de fácil acesso à equipe assistencial, no intuito de evitar que essa se desloque para além das áreas de isolamento (quarto ou coorte) para efetuar os registros de tomadas de decisão, diagnósticos e cuidados prestados aos pacientes com COVID-19.

Preferencialmente, os prontuários deverão permanecer no posto de enfermagem durante a internação do paciente e os formulários utilizados para registro (ex: evoluções, prescrições, folhas de sinais vitais e de balanço hídrico, folha de consumo, dentre outros) não deverão ser levados para a enfermaria/box/sala de procedimento.

Recomenda-se que, sempre que possível, todos os dados e cuidados aos pacientes com COVID-19 sejam registrados em prontuário eletrônico, com a intenção de otimizar o acesso às informações, fazendo com que o menor número possível de pessoas tenha contato com o prontuário físicos.

Recomenda-se que os prontuários físicos permaneçam em quarentena em local apropriado, em envelope de papel ou caixa de papelão, por 48 horas antes de serem encaminhados para outros setores do hospital.

Os prontuários deverão ficar em quarentena quando o paciente sair do isolamento (ou seja, depois dos 14 dias recomendados). Durante o transporte 
intra-hospitalar, não é recomendado que o prontuário entre em contato com o paciente e/ou com a maca de transporte.

Recomenda-se que o prontuário seja acondicionado em saco plástico transparente e limpo. A inserção e retirada do prontuário do saco plástico deve ser realizado por profissional que estiver com as mãos higienizadas. Aqueles que manusearem o prontuário físico antes do período de quarentena (48 horas) deverão utilizar EPI apropriado (máscara cirúrgica) e realizar a higiene de mãos logo em seguida

Ressalta-se que, antes mesmo da pandemia ser decretada pela Organização Mundial de Saúde (OMS) e a publicação da Nota Técnica da EBSERH, a Coordenadora do Projeto que vem sendo desenvolvido na HUPAA adotou as recomendações disseminadas pelos órgãos de saúde sobre o tratamento e manuseio dos prontuários de pacientes.

\section{PROCEDIMENTOS METODOLÓGICOS}

Foi utilizada a pesquisa exploratória, com abordagem qualitativa e, que realizou antes de tudo uma extensa pesquisa bibliográfica. Conforme Severino (2007, p.122) a pesquisa bibliográfica "é aquela que se realiza a partir do registro disponível decorrente de pesquisas anteriores em documentos impressos como livros, artigos, teses e etc."

Visto que as pesquisas exploratórias, de acordo com Severino (2007, p.123) são aquelas que buscam "apenas levantar informações sobre um determinado objeto, delimitando assim um campo de trabalho, mapeando as condições de manifestação desse objeto", o presente estudo procura levantar informações sobre as condições de gestão da informação com foco na preservação dos documentos de instituições de saúde, delimita o campo e ainda busca o entendimento das condições em que o acervo se encontra e os motivos que culminam com a situação encontrada. Já o método qualitativo é, segundo Minayo (2010, p.57), "o que se aplica ao estudo da história, das relações, das representações, das crenças, das percepções e das opiniões, produtos das interpretações que os humanos fazem a respeito de como vivem, constroem seus artefatos e a si mesmo, sentem e pensam". Assim, fica claro que este método se aplica adequadamente a proposta apresentada. 
O universo da pesquisa é composto por um total de 15 sujeitos e foi possível realizar uma amostra aleatória que contou com 10 participantes que são funcionários que atuam diretamente junto arquivo do SAME/UFAL/HUPAA/EBSERH.

Na presente pesquisa, utilizou-se o questionário, que de acordo com Lakatos e Marconi (2010) é "um instrumento de coleta de dados, constituído por uma série ordenada de perguntas, que devem ser respondidas por escrito e sem a presença do entrevistador". O questionário referido foi estruturado em três blocos de questões para a coleta dos dados qualitativos:

Bloco I - Capacitação: aborda questões relacionadas a treinamento para atuar no SAME/HUPAA e capacitação em gestão eletrônica de documentos;

Bloco II - Gestão da Informação: aborda questões sobre a gestão de informação e a organização dos prontuários de pacientes no SAME/HUPAA e a relevância do acondicionamento dos prontuários para a tomada de decisões dos gestores do HUPAA;

Bloco III - Conservação e Preservação: aborda questões relacionadas à higienização, estado físico, acondicionamento, digitalização, bem como a intervenção dos estagiários no processo de preservação dos prontuários de pacientes guardados pelo SAME/HUPAA.

Registra-se que a distribuição dos questionários foi realizada no período de fevereiro a março de 2019 e uma das dificuldades enfrentadas foi a demora para o recebimento deles. Contudo, o fator positivo é o de que todos foram devolvidos, ou seja, obtivemos $100 \%$ de resposta. Neste artigo apresentamos um recorte dos resultados que se encontram circunscritos no Bloco III do questionário aplicado.

\section{PRESERVAÇÃO, CONSERVAÇÃO E RESTAURAÇÃO DE DOCUMENTOS EM INSTITUIÇÕES NO HUPAA/UFAL/EBSERH}

Os trabalhos iniciaram com a higienização dos prontuários dos pacientes atendidos pela Expedição Norte-Americana do Navio SS Hope1, utilizando material adequado a esse fim, tais como: pincel, extrator de grampos, flanelas, fazendo a

\footnotetext{
${ }^{1}$ O Navio HOPE (a palavra HOPE era sigla da expressão HEALTH OPPORTUNITY FOR PEOPLE EVERYWERE que significa "oportunidade de saúde para todos os povos" (SANTOS, LIRA, NASCIMENTO, 2009, p.46).
} 
limpeza e retirando grampos, bailarinas e clips oxidados, desdobrando folhas, passando o pincel para retirar a sujidade depositada sobre o documento, como poeira. Por se tratar de um trabalho insalubre e por medidas de segurança, foram utilizado Equipamentos de Proteção Individual (EPI), que, de acordo com o Manual de Conservação Preventiva de Documentos (2005, p.31),

\begin{abstract}
são dispositivos de uso pessoal destinados a resguardar a saúde e a integridade física do trabalhador [...] podem ser classificados segundo a parte do corpo em que atuam: proteção para a cabeça (máscara, touca e óculos); proteção para o tronco (avental de mangas longas); proteção para os membros superiores (luvas); e proteção para os membros inferiores (botas), [...] a não utilização de EPIs durante a realização do trabalho, em locais que apresentam risco de contaminação à saúde do trabalhador, pode acarretar diversas manifestações alérgicas, como rinite, irritação ocular, problemas respiratórios etc..
\end{abstract}

Ressalta-se que esse trabalho foi realizado sob a supervisão da Coordenadora do Projeto que também é Coordenadora de Estágio Obrigatório do Curso de Biblioteconomia da UFAL, possibilitando a inserção de pelo menos 20 (vinte) discentes por semestre nas atividades do Projeto.

Assim, foi possível realizar as etapas pertinentes a primeira fase do projeto, qual seja o tratamento físico desses prontuários e a organização do espaço físico no qual os mesmos estão disponíveis, utilizando as recomendações exigidas pelas instituições de saúde, conforme registro a seguir (Figura 1):

Figura 1 - Utilização dos EPIs

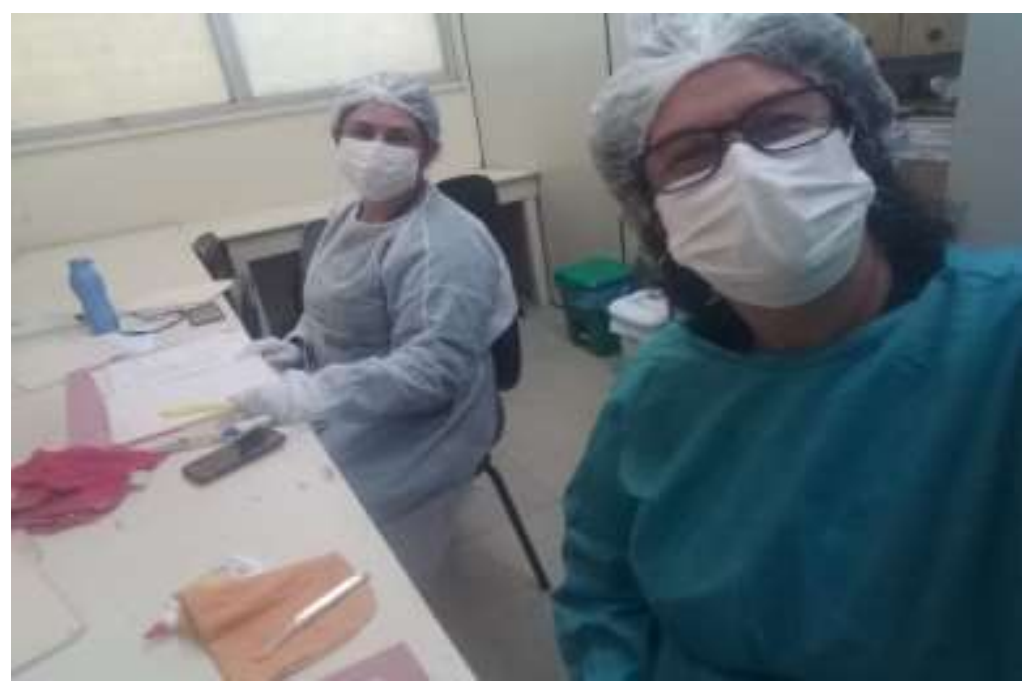

Fonte: Dados da pesquisa, 2019. 
Objetivando a preparação desses prontuários para a digitalização, foram removidos todos os grampos, clips ou materiais similares que viessem impedir a ação do scanner, bem como a deterioração maior do próprio documento (Figura 2). Estas medidas contribuem para evitar prejuízos no processo de conservação do acervo documental tratado.

Figura 2 - Sujidade removida dos prontuários

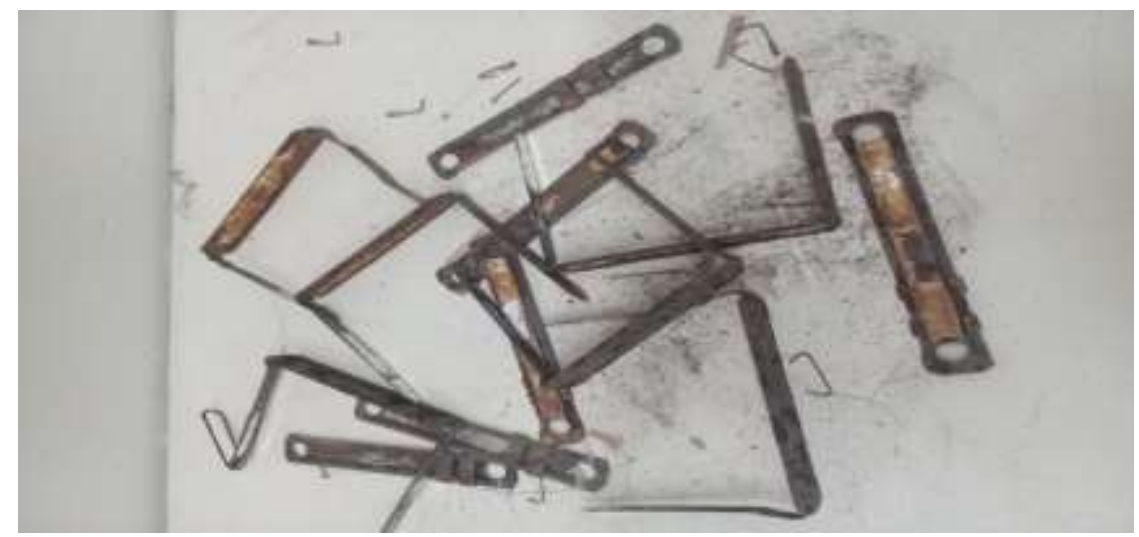

Fonte: Dados da pesquisa, 2019.

O processo de higienização é lento e requer o máximo de cuidado com os prontuários (Figura 3). Devido ao estado de guarda, muitos já sofreram ações de agentes externos que danificaram os documentos, tais como: agentes físicos, biológicos, ambientais e ação do homem (manuseio inadequado) e as más condições de acondicionamento desses prontuários.

Figura 3 - Higienização dos prontuários

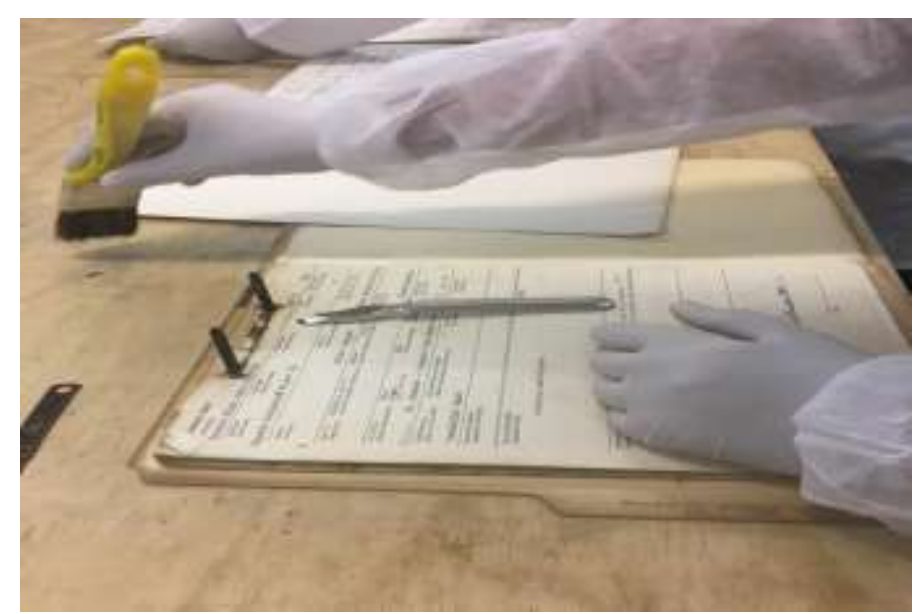

Fonte: Dados da pesquisa, 2019. 
Após esse processo de higienização, os prontuários foram acondicionados em caixas apropriadas com identificação e guardadas em local adequado, aguardando a etapa de digitalização.

Por último, a Restauração é o ato de recuperar o suporte do documento danificado e, dentro desse pensamento, Zúñiga (2002, p.73) usa o termo conservação/restauração para esse tipo de intervenção e o define como "[...] o exame do documento, seu tratamento, e a documentação desse tratamento". Outros autores, como Cunha (2008, p.323), diz que é a "[...] aplicação de técnicas para reparar documentos danificados, com a intenção de contribuir para sua preservação. Já Camargo e Bellotto (1996, p.67) citam a restauração como "[...] um conjunto de procedimentos específicos para recuperação e reforço de documentos deteriorados e danificados". Desse modo, podemos definir a restauração como um conjunto de medidas que visam a estabilização e a reversão dos danos físicos adquiridos pelo documento ao longo dos anos.

Figura 4 - Cafua antes da intervenção dos estagiários e equipe do SAME

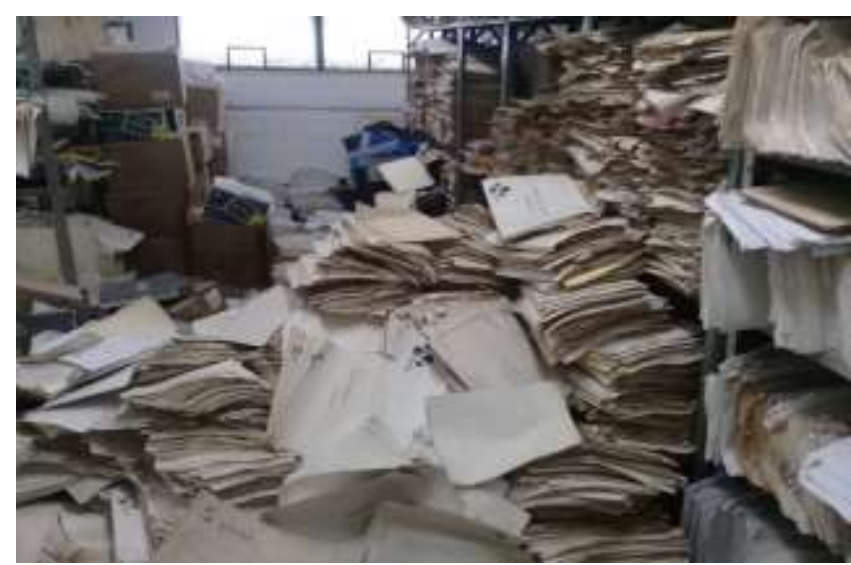

Fonte: Dados da pesquisa, 2019.

Figura 5 - Cafua após a intervenção dos estagiários e equipe do SAME

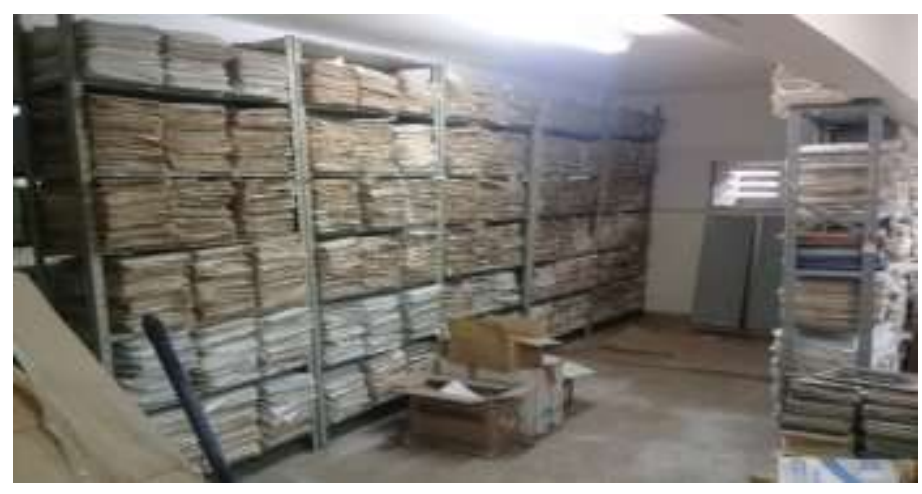

Fonte: Dados da pesquisa, 2019. 
Durante a organização dos prontuários dos pacientes foi indagado aos funcionários se eles teriam sugestões para a melhoria na conservação e preservação dos prontuários guardados pelo SAME/HUPAA, obteve-se $90 \%$ de respostas, sendo que um dos respondentes não quis opinar. Nessas respostas pode-se perceber que $70 \%$ apontam uma preocupação em relação à falta de espaço físico para o acondicionamento desses prontuários, bem como para o próprio arquivo do SAME, $20 \%$ das respostas mencionam a permanência dos estagiários dentro do SAME, executando o trabalho de higienização para a digitalização, sendo visto como um grande avanço na melhoria do arquivo.

A conscientização dos respondentes é unânime ao afirmarem sobre a importância e permanência dos estagiários na intervenção para conservação e preservação dos prontuários através da higienização por ser um processo inexistente no SAME/HUPAA. Apontam a falta de espaço físico como uma das causas do acondicionamento inadequado dos prontuários inativos, e que a intervenção dos estagiários do Curso de Biblioteconomia é de suma importância na higienização, sendo visto como um grande avanço na melhoria do arquivo para um futuro processo de digitalização dos prontuários, mantendo, assim, a salvaguarda da memória institucional.

\section{CONSIDERAÇÕES FINAIS}

A informação em saúde evolui com rapidez em comparação às outras áreas, fazendo-se necessário adotar métodos para armazenar, tratar e disseminar a informação, utilizando-se ferramentas que auxiliem na tomada de decisão, melhorando a gestão hospitalar. Sendo o SAME um dos mais importantes e estratégicos setores de atividades dentro de qualquer instituição de saúde, faz-se fundamental o gerenciamento documental, proporcionando maior nível de segurança no tratamento, acondicionamento, disponibilização e acesso às informações referentes ao prontuário de pacientes, possibilitando melhorias no processo de trabalho e assistência aos pacientes.

No contexto da instituição estudada, o montante de documentos impressos cresce vertiginosamente, o resultante dessa produção não consegue ser armazenado 
e acondicionado de forma adequado devido à falta de espaço físico. As novas tecnologias, surgem com uma proposta de armazenamento e preservação documental possibilitando acesso rápido às informações, o que demanda investimentos em equipamentos e softwares. Para atender essa demanda, se faz necessário uma política de Gestão e Preservação de Documentos utilizando a preservação e conservação através da higienização.

Constatou-se que o sistema organizacional manual na disposição dos terminais dentro do SAME/HUPAA/UFAL/EBSERH, numerados de 0 a 10, facilita o acesso aos prontuários, e auxilia na tomada de decisão dos gestores.

A guarda dos prontuários pelo SAME/HUPAA/UFAL/EBSERH é de extrema relevância para as atividades do hospital, uma vez que guardam também o histórico de assistência ao paciente revelando a importância na gestão de documentos $A$ digitalização dos prontuários guardados pelo SAME/HUPAA/UFAL/EBSERH é um objetivo a ser alcançado, mas para tanto se faz necessária a conscientização para preservação e conservação dos documentos. As condições de higienização desses prontuários apontam um grau elevado de preocupação, pois se encontram em péssimo estado de conservação.

Ante ao exposto, a possibilidade de digitalização incidirá em grandes benefícios, pois preservará os documentos, reduzirá espaço, facilitará na recuperação da informação, evitará perdas e viabilizará pesquisas científicas.

Os prontuários guardados pelo SAME/HUPAA/UFAL/EBSERH no arquivo inativo, cafua, se encontravam em péssimas condições de acondicionamento, em estado de abandono. A intervenção dos estagiários e equipe do SAME, através da parceria do Hospital Universitário com o Curso de Biblioteconomia da UFAL, resultou numa melhoria significativa com a reorganização das estantes e da guarda dos prontuários em caixas, onde se encontram aguardando higienização para futura digitalização. Além disso, é possível afirmar que a realização de projetos com parcerias desta natureza é fundamental para se tentar minimizar os danos causados pela inobservância do valor histórico, administrativo e assistencial dos prontuários de pacientes.

Visto todo 0 exposto em relação às condições do SAME/HUPAA/UFAL/EBSERH, salienta-se a necessidade da preservação e 
conservação dos prontuários guardados pelo mesmo para a salvaguarda da memória institucional do Hospital Universitário, já que são documentos que retratam a história da saúde e da sociedade alagoana. Neste sentido, o Curso de Biblioteconomia da UFAL pode contribuir ainda mais para a melhoria da situação atual. Nesse sentido, novas pesquisas podem ser empreendidas com o intuito de discutir soluções para os complexos problemas que afetam a gestão documental no âmbito das instituições de saúde de Alagoas, seja no âmbito público ou privado.

\section{REFERÊNCIAS}

BRASIL. Lei n 8.159, de 08 de janeiro de 1991. Diário Oficial da União, Brasília, 2004. Disponível em: http://www.arquivonacional.gov.br/conarq/leis/leg_arq.html. Acesso em: 23 out. 2018.

CAMARGO, A. M. A.; BELLOTTO, H. L. Dicionário de terminologia arquivística. São Paulo: AAB,1996.

CONSELHO FEDERAL DE MEDICINA. Resolução no 1.246, de 08 de janeiro de 1988. Código de ética médica. Disponível em http://www.portalmedico.org.br/resolucoes/cfm/1988/1246_1988.htm. Acesso em: 25 ago. 2019.

CONSELHO NACIONAL DE ARQUIVOS - CONARQ (Brasil). Câmara Técnica de documentos eletrônicos. Modelo de requisitos para sistemas informatizados de gestão arquivística de documentos - eArq. 2011. Disponível em:

http://www.documentoseletronicos.arquivonacional.gov.br/media/e-arq-brasil-2011corrigido,pdf. Acesso em: 23 out. 2018.

CONSELHO NACIONAL DE ARQUIVOS - CONARQ (Brasil). Recomendações para Digitalização de Documentos Arquivísticos Permanentes. Rio de Janeiro, 2010. 27p. Disponível em:

http://www.conarq.arquivonacional.gov.br/media/publicacoes/recomendaes_para_a_ digitalizao.pdf. Acesso em: 25 ago. 2019.

CUNHA, M. B.; CAVALCANTE, C. R. O. Dicionário de Biblioteconomia e Arquivologia. Brasília: Briquet de Lemos Livros, 2008.

FONSECA, M. O. K. Arquivologia e Ciência da Informação. Rio de Janeiro: Editora FGV, 2005.

FRANÇA, P. Z. P. Reestruturação do serviço de arquivo médico e estatística do centro municipal de referência em saúde Leonard Mozart da prefeitura municipal de Cabedelo. 2104. 58f. Monografia (Graduação em Arquivologia) - 
Universidade Federal da Paraíba, Centro de Ciências Sociais Aplicadas, João Pessoa, 2014. Disponível em:

https://repositorio.ufpb.br/jspui/handle/123456789/1185. Acesso em: 23 ago. 2019.

LAKATOS, E. M.; MARCONI, M. Fundamentos de metodologia científica. 7. ed. São Paulo: Atlas, 2010. 297 p.

MANUAL DE CONSERVAÇÃO DE DOCUMENTOS: papel e filme / texto Dione Seripierrin ... [et al.]. São Paulo: Editora da Universidade de São Paulo, 2005.

MOTA, F. R. L. Nota técnica: descarte de documentos do HUPAA/UFAL/EBSERH. Maceió: Hospital Universitário Professor Alberto Antunes, 2018.

MOTA, F. R. L; PEREIRA, E. M. S. Tratamento e organização dos prontuários de pacientes do HUPAA/UFAL/EBSERH. Maceió: Hospital Universitário Professor Alberto Antunes, 2018.

MINAYO, M. C. S. O desafio do conhecimento: pesquisa qualitativa em saúde. 12. ed. São Paulo: Hucitec, 2010.

PAES, M. L. Arquivo: teoria e prática. 3. ed. Rio de Janeiro: FGV, 2004.

SANTOS, N. M.; FREIXO, A. L. A gestão do prontuário do paciente com ênfase na atuação da comissão de revisão de prontuários. In: SIMPÓSIO BAIANO DE ARQUIVOLOGIA, 3., 2011, Salvador. Anais[...] Salvador, 2011. p.1 - 12.

SEVERINO, A. J. Metodologia do trabalho científico. 23. ed. São Paulo: Editora Cortez, 2007.

ZÚÑIGA, S. S. G. A importância de um programa de preservação em arquivos públicos e privados. Registro: Revista do Arquivo Público Municipal de Indaiatuba, Indaiatuba, Ano 1, v. 1, n. 1, p. 71-89, 2002. 